\title{
Diaspora Masyarakat Keturunan Arab di Jakarta
}

\author{
Zulkarnen $^{1}$ \\ ${ }^{1}$ Program Studi Sastra Arab, Fakultas Sastra, Universitas Al Azhar Indonesia, \\ Jalan Sisingamangaraja, Kompleks Masjid Agung Al Azhar, Kebayoran Baru, Jakarta 12110 \\ Penulis untuk Korespondensi/E-mail: zulkarnen@uai.ac.id
}

Abstrak - Diaspora adalah penyebaran orang dari satu negara asli ke negara lain (Cambridge Dictionary, 2017), sementara Sujatmiko (2014: 55) memberikan definisi yang sedikit berbeda dengan menyebutnya sebagai istilah yang mengacu pada bangsa atau penduduk etnis yang dipaksa atau dipaksa untuk meninggalkan tanah air tradisional etnik; penyebaran mereka di berbagai belahan dunia; dan perkembangan yang telah dihasilkan karena budaya dan penyebarannya. Masyarakat Arab menjunjung tinggi peraturan dan menjalankannya sama seperti menjalankan perintah Tuhan dan yang memecahnya berarti menghina Garda Tertinggi (Hitti, 2010), ini menjadi dasar studi budaya Arab di mana konsep masyarakat egalitarian dan geografi tandus dengan gurun khas merupakan faktor utama. Dalam membentuk karakter dan kepribadian yang keras dan pantang menyerah. Setelah melakukan Diaspora ke Indonesia khususnya di Jakarta, terjadi beberapa hal menarik untuk dipelajari secara kultural sehingga dalam penelitian ini terbatas pada penyebab diaspora, pemetaan permukiman mereka, dan pelestarian budaya mereka di Jakarta. Studi ini akan melakukan beberapa langkah untuk menyiapkan data awal yang akan digunakan untuk berbagai studi budaya melawan masyarakat keturunan Arab oleh pihak-pihak yang berkepentingan. Diharapkan hasil penelitian ini dapat membantu dan mempermudah masyarakat dalam membaca, mengeksplorasi, dan memahami masyarakat keturunan Arab dan mengungkapkan banyak sisi budaya mereka yang kaya akan filsafat esensial.

\section{Kata Kunci - Diaspora, Arab, Budaya}

Abstract - Diaspora is the spreading of people from one original country to other countries (Cambridge Dictionary, 2017), while Sujatmiko (2014: 55) gave slightly different definition by calling it as a term that refers to nation or forced or encouraged ethnic population to leave their traditional ethnic homeland; their deployment in various parts in the world; and the development that has been generated because of their culture and deployment. Arab society upholds the rules and runs it as same as runs God's command and who break it means insulting The Supreme Guard (Hitti, 2010), it becomes fundamental of Arab culture study where egalitarian society concept and barren geography with desert typical are a major factor in shaping loud character and personality and unyielding. After doing Diaspora to Indonesia especially Jakarta, it happened several interesting things to be culturally studied that in this study is limited in the cause of diaspora, mapping of their settlement, and the preservation of their culture in Jakarta. The study will do several steps preparing an initial data that will be utilized to various culture studies against society of Arab descendant by any interested parties. It is expected the result of the study can help and make easier the people in reading, exploring, and understanding the society of Arab descendant and reveal many of their culture sides that rich in essential philosophy. 


\section{PENDAHULUAN}

$\mathrm{D}$ iaspora is the spreading of people from one original country to other countries (Cambridge Dictionary, 2017) [1], sejalan dengan definisi ini, KBBI (Kamus Besar Bahasa Indonesia) menjelaskan bahwa diaspora adalah masa tercerai-berainya suatu bangsa yang tersebar di berbagai penjuru dunia dan bangsa tersebut tidak memiliki negara (http://kbbi.web.id/diaspora). Sujatmiko (2014 : 55) memberikan definisi yang sedikit berbeda dengan menyebutnya sebagai istilah yang merujuk kepada bangsa atau penduduk etnis yang terpaksa atau terdorong untuk meninggalkan tanah air etnis tradisional mereka; penyebaran mereka di berbagai bagian lain dunia; dan perkembangan yang dihasilkan karena penyebaran dan budaya mereka.[3]

Masyarakat terdiri atas individu-individu manusia yang membentuk atau dibentuk oleh organisasi dapat dikemukakan bahwa masyarakat adalah manusia-organisasi (Sumodiningrat, 2005: 112), oleh karena itu masyarakat adalah perpaduan antara heterogenitas dan keteraturan, sehingga masyarakat merupakan bentuk paling modern dari peradapan manusia hingga saat ini, dari bentuk awalnya komunitas (homogen) berkembang menjadi massa (heterogen-takteratur) dan membentuk masyarakat (heterogen-teratur). [4]

Masyarakat Arab sangat menjunjung tinggi aturan-aturan dan menjalankannya sama dengan menjalankan perintah Allah dan melanggarnya berarti menghina Yang Maha Penjaga (Hitti, 2010), inilah yang menjadi sandaran kajian budaya Arab dimana konsep masyarakat yang egaliter dan geografi tandus khas padang pasir merupakan faktor utama dalam membentuk karakter dan kepribadian yang keras dan pantang menyerah. [5]

Setelah melakukan diaspora ke Indonesia khususnya Jakarta, terjadi beberapa hal yang menarik untuk dikaji secara budaya tentang keturunan Arab dalam menjalani kehidupan mereka, yang pada penelitian ini kami batasi pada penyebab diaspora, pemetaan pemukiman mereka, khususnya di Jakarta dan pemertahanan budaya karena penyebaran mereka di Jakarta.
Penelitian ini akan melakukan sejumlah langkah guna menyiapkan suatu data awal yang nantinya dapat dimanfaatkan untuk berbagai kajian kebudayaan terhadap masyarakat keturunan Arab oleh berbagai pihak yang berminat kepada kajian Budaya Arab. Diharapkan agar hasil kajian ini nantinya dapat membantu mempermudah masyarakat dalam membaca, mendalami, dan memahami Masyarakat keturunan Arab dan menyingkap banyak sisi kebudayaan mereka yang kaya akan filosofi penting seputar ajaran dan nilai Islam.

\section{KERANGKA TEORI}

Diaspora is the spreading of people from one original country to other countries (Cambridge Dictionary, 2017) [2], sejalan dengan definisi ini, KBBI (Kamus Besar Bahasa Indonesia) menjelaskan bahwa diaspora adalah masa tercerai-berainya suatu bangsa yang tersebar di berbagai penjuru dunia dan bangsa tersebut tidak memiliki negara.

Sujatmiko (2014: 55) memberikan definisi yang sedikit berbeda dengan menyebut diaspora sebagai istilah yang merujuk kepada bangsa atau penduduk etnis yang terpaksa atau terdorong untuk meninggalkan tanah air etnis tradisional mereka; penyebaran mereka di berbagai bagian lain dunia; dan perkembangan yang dihasilkan karena penyebaran dan budaya mereka. L2[3]

Istilah diaspora dalam penggunaannya, masih sering terjadi pertentangan diantara para ahli, apabila kita merujuk pada istilah Islam maka, akan lebih akrab dengan istilah hijrah, dan hijrah ini merupakan anjuran yang baik untuk dilakukan dalam Islam, sehingga tidak diragukan lagi masyarakat Arab pada waktu itu melakukan perjalanan ke nusantara dalam rangka menjalankan perintah hijrah di atas, yang akan kami deskripsikan lebih lanjut pada pembahasan.

Masyarakat adalah perpaduan antara heterogenitas dan keteraturan, sehingga masyarakat merupakan bentuk paling modern dari peradaban manusia, dari bentuk awalnya komunitas (homogen) berkembang menjadi massa (heterogen-tak-teratur) dan membentuk masyarakat (heterogen-teratur). Masyarakat sendiri terdiri atas individu-individu manusia 
yang membentuk atau dibentuk oleh organisasi dapat dikemukakan bahwa masyarakat adalah manusia-organisasi (Sumodiningrat, 2005: 112). [4]

Kajian budaya Arab menyandarkan konsep masyarakat pada sistem egaliter yang terbentuk dari geografi yang tandus sehingga terbentuk karakter dan kepribadian yang keras dan pantang menyerah. Masyarakat Arab sangat menjunjung tinggi aturan-aturan dan menjalankannya sama dengan menjalankan perintah Allah dan melanggarnya berarti menghina Yang Maha Penjaga (Hitti, 2010), teori ini kami analisis pada pembahasan berikut guna melihat sejauh mana mereka mampu mempertahankannya sementara negeri yang mereka tinggal saat ini sangat jauh berbeda dengan negeri asal mereka. [5]

\section{PEMBAHASAN}

Pada pembahasan diaspora masyarakat keturunan Arab banyak hal yang dapat dijadikan pokok pembahasan, kesempatan kali ini kami memberikan batasan pembahasan pada penyebab diaspora, pemetaan pemukiman mereka dan pemertahanan budaya karena penyebaran mereka di Jakarta. Sesuai dengan pendahuluan yang kami telah sampaikan bahwa penelitian ini diharapkan menjadi landasan awal untuk penelitian budaya masyarakat keturunan Arab di Indonesia khususnya di Jakarta, yang masih sedikit jumlahnya.

\section{Penyebab Diaspora}

Masyarakat Arab adalah salah satu rumpun bangsa besar di dunia yang melakukan diaspora, diaspora masyarakat Arab terjadi karena adanya beberapa penyebab, diantaranya perniagaan, penyebaran agama, peperangan, ataupun pengungsian yang diakibatkan konflik berkepanjangan yang terjadi di beberapa negara Arab pada abad pertengahan (Goldschmidt: 1983). [6]

Masyarakat Arab di Indonesia sering disandingkan dengan penyebaran Islam (Hamka: 2016), yang pada abad ke VII M atau tahun pertama Islam, mereka telah datang ke negeri-negeri Melayu [7]. Sejarah masuknya Islam ke Indonesia terutama sejarah perkembangannya tidak terlepas dari sejarah masuknya perantau Arab. Masuknya agama rahmatan lil 'aalamiin ini melalui jalur perniagaan yang selama ini dijadikan teori awal ternyata didukung oleh beberapa alasan lainnya yang telah kami sebutkan di atas bahwa ada kepentingan untuk menjalankan perintah agama yaitu menyebarkannya, namun ada juga alasan yang kami bagi menjadi dua yaitu: faktor internal yaitu terjadinya perang antar golongan dalam umat Islam saat itu yang menyebabkan kelompok yang kalah untuk segera mencari tempat tinggal baru (Fromkin: 1989) [8], dan faktor eksternal yaitu perang salib yang tidak kunjung selesai selama 2 abad (Hillenbrand: 1999) [9] yang menyebabkan peralihan Palestina dari pusat dagang menjadi medan perang dan serbuan Mongolia ke Baghdad yang menyebabkan masyarakat Arab pada waktu itu lebih memilih untuk melakukan diaspora ke nusantara yang jauh dari perang dan memiliki sumber daya alam yang kaya.

Perlahan masyarakat Arab dapat diterima di Tanah Air yang saat itu masih kuat pengaruh Hindu-Budha. Sampai saat Samudra Pasai berdiri menjadi kerajaan Islam pertama dan terus berkembang kerajaan Islam lainnya tidak lepas dari peran masyarakat Arab yang mendiami kawasan itu. Berdirinya kerajaan Islam di Indonesia ini sekaligus memperkuat dugaan bahwa Islam masuk ke Indonesia secara sukarela dibawa oleh masyarakat Arab yang mulanya datang membeli rempah-rempah yang diperlukan dan akan dijual. Penghidupan mereka sebagai pedagang yang membawa barang-barang dari Arab dan pulangnya membawa rempah-rempah.

Masyarakat Arab yang bermukim di Nusantara sebagian besar berasal dari Hadramaut, dan sebagian lagi ada yang berasal dari Maskat, tepian Teluk Persia, Yaman, Hijaz, Mesir atau dari pantai Timur Afrika. Mereka menjadi pedagang perantara, pedagang kecil, pemilik toko, menembus pasar dan menyediakan barang dan jasa yang tidak dilakukan pendatang dari Eropa, juga melakukan kegiatan meminjamkan uang (Sulistiono: 2012).

Para masyarakat Arab mulai datang secara massal ke Nusantara pada tahun-tahun terakhir abad ke-18, tetapi mereka mulai banyak menetap di pulau Jawa setelah tahun 1820 . sejak permulaan abad-19 masyarakat Arab sudah bermukim di kota-kota Maritim di Indonesia khususnya di Batavia yang saat ini 
disebut Jakarta, umumnya mereka adalah para pedagang.

\section{Pemetaan Pemukiman}

Masyarakat Arab berdagang dan menghabiskan waktu berbulan-bulan untuk menjual barang dagangannya sampai habis agar bisa membeli barang dagangan setempat dan membawanya kembali ke negerinya masing-masing. Selain itu pelayaran yang mereka lakukan untuk kembali ke negeri asal tergantung pada musim, karena jarak antara Indonesia dan Jazirah Arab sangat jauh dan amat ditentukan oleh cuaca.

Pada awalnya mereka merantau ke Indonesia tanpa membawa istri-istrinya dan seluruhnya terdiri dari laki-laki baik tua maupun muda dan anak-anak. Awalnya mereka menetap berkelompok di perkampungan di dekat pelabuhan kota saat itu di Batavia atau Jakarta (sebutan saat ini) dinamakan pelabuhan Sunda Kelapa. Melalui sebab di atas terjadi hubungan antar kelompok pedagang masyarakat Arab dengan masyarakat pribumi yang terwujud secara bertahap.

Kondisi mereka yang merantau sendiri tanpa istri dan waktu tunggu yang lama menyebabkan mereka menjalin hubungan kekeluargaan dengan pribumi melalui pernikahan, kemudian beranak-pinak dan tidak kembali lagi ke negeri asal mereka yang sedang dilanda perseturuan antar kelompok ataupun mendapat serangan baik dari tentara salib ataupun tentara Mongol.

Hubungan sosial antara masyarakat Arab dengan penduduk setempat melalui hubungan perkawinan ini merupakan faktor utama yang menyebabkan mereka melakukan diaspora khususnya pernikahan yang dilakukan kepada penduduk pribumi golongan bangsawan atau pedagang besar yang pada saat itu sangat bangga apabila dapat mengambil menantu atau ipar dari kalangan masyarakat Arab terutama dari kalangan Sayid. Dari hubungan perkawinan ini banyak di antara masyarakt keturunan Arab yang kemudian diangkat menjadi penguasa daerah seperti Pontianak, Demak, Cirebon dan Mataram. Ini membuktikan bahwa mereka tidak hanya berperan sebagai pedagang, tapi juga sebagai ulama yang berdakwah dalam menyiarkan ajaran tauhid di Indonesia khsususnya di Jakarta salah satunya melalui jalan perkawinan.
Jalan lain yang dilakukan adalah dengan membangun masjid sebagai sarana dakwah seperti yang dilakukan oleh Habib Husein bin Abu Bakar Alaydrus membangun masjid, yang kini tersebut dikenal dengan Masjid Luar Batang. Masjid Luar Batang awalnya berupa bangunan mushalla, didirikan sekitar abad ke XVIII di Kota Tua Jakarta, tepatnya daerah Pasar Ikan hingga sekarang di Kelurahan Pejaringan, Jakarta-Utara. tepatnya beralamat di Jl. Luar Batang V No. 1, Rt. 004/Rw. 003, Jakarta 14440. Langkah mendirikan bangunan Masjid memang memiliki peran yang strategis, antara lain tempat kaum Muslimin: beribadah dan mendekatkan diri kepada Allah SWT, beri'tikaf, membersihkan diri, menggembleng batin untuk membina kesadaran dan mendapatkan pengalaman keagamaan sehingga selalu terpelihara keseimbangan jiwa dan raga serta keutuhan kepribadian, tempat bermusyawarah kaum Muslimin guna memecahkan persoalan-persoalan yang timbul dalam masyarakat, tempat berkonsultasi, mengajukan kesulitan-kesulitan, meminta bantuan dan pertolongan, tempat membina keutuhan ikatan jama'ah dan kegotong royongan di dalam mewujudkan kesejahteraan bersama, tempat pembinaan dan pengembangan kader-kader pimpinan umat, tempat pengaturan dan kegiatan sosial (Sulistiono: 2012). [10]

Dari jalan pernikahan dan jalan dakwah tersebut sangat menentukan pemukiman yang didiami oleh masyarakat keturunan Arab khususnya di Jakarta, menurut hasil survey mengenai jumlah masyarakat Arab di Jakarta pada tahun 1885, yakni sekitar 1.448 jiwa (Mobini: 1999) [11] wilayah Pekojan yang ditetapkan oleh pemerintahan Kolonial Belanda sebagai wilayah terkonsentrasi dan ketat perizinan, seperti halnya yang dapat ditemui di Kampung Arab Surabaya serta kota lainnya.

Pekojan di Jakarta Barat yang berdekatan dengan Pelabuhan Sunda Kelapa menjadikannya rujukan transit, juga berdekatan dengan Pecinan di Glodok, memudahkan terjalinnya hubungan dagang. Wilayah Pekojan awalnya dari pemukiman India Muslim Khwaja.

Baru pada tahun 1840-an, kelompok masyarakat keturunan Arab mulai menetap di wilayah ini ketika melakukan perdagangan kain katun, batu mulia, minyak wangi, hingga bisnis 
properti. Terdapat sebuah Masjid lama bernama Langgar Tinggi milik seorang Kapten Arab yang cukup kaya dan disegani, Syeikh Said Naum. Juga tercatat beberapa nama kapten Arab lainnya di wilayah ini, yakni Umar bin Hassan bin Ahmad Aidit, Umar bin Yusuf Manggus, dan Hasan bin Saleh Argubi.

Salah seorang Sultan dari Hadhramaut yang bernama Mansyur bin Ja'far Al Katiri pada akhir 1800an mendatangi Pekojan dan terkejut melihat jumlah masyarakat Arab di Pekojan begitu besarnya, di mana sebuah rumah hingga menampung 20 anggota keluarga.

Sang sultan kemudian berinisiatif untuk membuka wilayah baru untuk masyarakat Arab ini, hingga menjadikan wilayah Wijk Krukut Onderdistrict Penjaringan (kini Krukut) sebagai pemukiman Arab berikutnya. Di wilayah antara Pekojan dan Krukut yang kala itu masih berupa rawa, Sultan Mansyur secara bertahap membuka jalan dan membayar berupa uang real kepada Belanda, hingga wilayah ini dikenal dengan nama Tanah Sereal. Di sini juga diketahui terdapat Jembatan Lima, yang masih dikenal hingga saat ini.

Di dekat Masjid Langgar Tinggi, terdapat sebuah jembatan bernama Jembatan Kambing yang membelah Sungai Angke. Disebutnya demikian karena jembatan ini memiliki sejarah panjang perihal perdagangan kambing sebagai salah satu kegemaran masyarakat keturunan Arab secara turun menurun. Kambing-kambing disini diyakini banyak didatangkan dari Tegal, dan dikirim ke penjagalan di salah satu kampung di Pekojan, yang hingga saat ini masih bernama Kampung Pejagalan.

Perkembangan berikutnya, wilayah Pekojan sering dilanda banjir hingga setelah dihapusnya sistem pemukiman pada 1919, banyak pendatang Arab keluar dan menyebar ke Krukut, Sawah Besar, Tanah Abang, hingga Kwitang. Saat ini, wilayah Pekojan tak lagi didiami pendatang Hadharim, yang hanya tersisa sekitar 25 persen dari keseluruhan populasi. Wilayah ini bahkan didominasi keturunan Tionghoa, meski masih banyak meninggalkan bukti sejarah perkembangan masyarakat India, Moor, dan Arab.
Tahun-tahun berikutnya, masyarakat Arab mulai menyebar lebih jauh, hingga ke Bogor, dimana terdapat Kampung Arab Pekojan, kemungkinan adalah lokasi menetapnya orangorang Arab dari Pekojan Jakarta. Nama kampung yang sama juga bisa ditemui di Banten dan Semarang.

Dari deskripsi di atas dapat kita ketahui bahwa pemukiman masyarakat keturunan Arab di Batavia (sekarang Jakarta) awalnya sesuai dengan peraturan Pemerintah Hindia Belanda yang sangat ketat terkonsentrasi pada tiga daerah yaitu daerah Pekojan, Krukut, dan Tanah Abang. Seiring perkembangannya masyarakat keturunan Arab di Jakarta dapat ditemukan juga bermukim di sejumlah tempat, misalnya Kwitang, Condet, Kampung Melayu dan sebagainya.

\section{Pemertahanan Budaya}

Ulama mempunyai pengaruh di Batavia khususnya dari kalangan masyarakat keturunan Arab, diantaranya; Habib Husein bin Abi Bakr bin Abdullah al-Aydrus (w. 1756), di Luar Batang, Jakarta Utara, Habib Abdurrahman bin Abu Bakar al-Habsyi (1828-1853). Habib Muhammad Jabarti (w. 1855), Salim bin Abdullah bin Somair (w. 1854) yang telah menghasilkan sebuah karya popular di kalangan Muslim Betawi dan daerah lainnya dengan tema Safinah an-Najah, dan seorang ulama yang cukup disegani di kalangan ulama Nusantara serta Pemerintah Hindia Belanda ialah Sayyid Utsman bin Abdullah bin Aqil bin Yahya al-Alawy.

Melalui keteladanan mereka, memberikan dorongan dan inspirasi bagi para generasi selanjutnya untuk menjadi Ulama (Daftari: 2011) [12]. Di lingkungan masyarakat Betawi (sebutan masyarakat pribumi Jakarta), lahir ulama handal seperti KH Abdullah Syafi i, KH Tohir Rohili, KH Fathullah Harun, KH Hasbialloh, KH Ahmad Zayadi Muhajir, KH Achmad Mursyidi, Syekh KH Muhammad Muhadjirin Amsar Ad-Dary, mu`allim KH M Syafi i Hadzami, dan mu`allim Rasyid berguru kepada habaib terkemuka di Jakarta, yaitu kepada Habib Ali Bin Abdurrahman Al-Habsyi (dikenal dengan nama Habib Ali Kwitang) dan kepada Habib Ali Bin Husien Al-Attas (dikenal dengan nama Habib Ali Bungur). 
Malalui jalur akulturasi dengan ritual-ritual keagamaan yang diadakan di lingkungan masyarakat Betawi dengan mempertemukan masyarakat pribumi sekitar dengan masyarakat keturunan Arab seperti shalat Jum'at di mana pada momen ini terjadi pembauran yang cukup intensif oleh kedua masyarakat tersebut.

Para ulama masyarakat Arab telah memainkan peranan penting dalam proses dan perkembangan Islam di kalangan masyarakat Betawi, ditandai tersebarnya majlis-majlis taklim mereka yang telah diikuti oleh masyarakat pribumi (Betawi).

Jasa yang lain dengan adanya masyarakat keturunan Arab yang menetap di Batavia telah berasimilasi dan berakulturasi dengan budaya masyarakat setempat sehingga melahirkan kebudayaan Betawi yang bernafaskan Islami seperti kesenian musik gambus, di mana dalam setiap acara khususnya pada perkawinan ditampilkan untuk memeriahkan acara tersebut. Di saat sekarang, gambus melahirkan sebuah seni musik yang disebut Marawis karena komponen alat musiknya terdiri dari gendanggendang kecil (Marwas) yang dipakai dalam seni musik gambus. Seni rebana, dan tari Zapin tidak ketinggalan hadir di tengah masyarakat Betawi.

Budaya masyarakat Arab lainnya yang biasa digunakan khususnya pada acara ritual keagamaan yaitu pemakaian gamis (qamis) berupa jubah panjang berwarna putih dengan (iqal) igal yang juga berwarna putih diikatkan di kepala.

Penggunaan bahasa pasaran (suqiyah) Arab dan terlepas dari gramatika bahasa Arab (Barakat: 1993) [13]. Terkadang bahasa Indonesia dalam percakapannya disisipi bahasa Arab, seperti "Ente (kamu) mau dibikinin gahwah (qohwah) kopi”, kemudian kata "harim" untuk ditujukan kepada wanita, kata "syahi" yang berarti teh menjadi bahasa percakapan keseharian mereka dan dipadu dengan bahasa Indonesia.

Masyarakat keturunan Arab berbeda dengan pendahulunya yang telah berasimilasi total dengan pribumi khususnya masyarakat betawi. Tetapi dalam beberapa hal seperti memilih mempelai pria untuk anak perempuannya masih sangat selektif dan sangat mengharapkan mendapatkan menantu dari golongannya (Farukh: 1996). [14]

Hitti (2010) menjelaskan hal tersebut sebagai upaya menjaga darah, pemahaman mereka terhadap hubungan patrilineal memberikan kelonggaran kepada putra mereka tetapi ketat terhadap putri mereka, khususnya dalam memilih pasangan hidup. [5]

Nasabiyah (klan) masih sangat mereka perhatikan (Al-Omari: 2008), khususnya dalam kalangan mereka dengan membaginya setidaknya ke dalam dua golongan besar yaitu golongan sayid yang dikenal sebagai keturunan Nabi Muhammad saw. dari nasab Hasan ataupun Husain dan golongan syeh yaitu sebutan bagi mereka yang bukan sayid. [15]

Setidaknya kedua hal tersebut di atas yang membuat masyarakat keturunan Arab belum dapat sepenuhnya dapat membaur dengan pribumi khususnya masyarakat betawi. Meskipun tidak dapat dipungkiri pengaruh mereka khususnya dalam bidang keagamaan masih dominan di masyarakat pribumi khususnya masyarakat Betawi tetapi terkesan masih ada jarak yang sangat tegas antara keduanya.

\section{KESIMPULAN DAN SARAN}

Tidak seperti penelitian sebelumnya yang mayoritas menyebutkan bahwa masuknya Islam ke Indonesia hanya melalui para pedagang Gujarat, tetapi pada penelitian ini mencoba memberikan gambaran bahwa pengaruh masyarakat Arab mulai awal abad keVII M sudah ada di Indonesia, khususnya di Jakarta yang saat ini sangat terasa besarnya pengaruh keturunan Arab dibandingkan keturunan lainnya di masyarakat ibu kota.

Adapun penyebab terjadinya diaspora adalah bukan hanya karena perniagaan seperti yang banyak kita baca pada tulisan-tulisan sebelumnya, tetapi penelitian ini memberikan deskripsi bahwa ada upaya penyebaran agama Islam sebagai unsur utama, yang didukung pula oleh dua faktor yang ikut mempengaruhi yaitu faktor internal terjadi persaingan antar golongan umat Islam di jazirah Arab khususnya setelah wafatnya Rasulullah saw. yang menyebabkan perang saudara (Aziz: 2011), dan 
faktor eksternal adalah serangan tentara salib dan serbuan Mongolia yang berkepanjangan menyebabkan instabilitas kehidupan mereka di sana, sehingga Indonesia khususnya Jakarta menjadi alternatif hunian yang menjanjikan.[16]

Pemetaan pemukiman masyarakat keturunan Arab di Batavia (sekarang Jakarta) awalnya sesuai dengan peraturan Pemerintah Hindia Belanda yang sangat ketat terkonsentrasi pada tiga daerah yaitu daerah Pekojan, Krukut, dan Tanah Abang. Seiring perkembangannya masyarakat keturunan Arab di Jakarta dapat ditemukan juga bermukim di sejumlah tempat, misalnya Kwitang, Condet, Kampung Melayu dan sebagainya.

Pemertahanan budaya mereka sangatlah terasa hingga saat ini, terdapat yang berasimilasi secara total bahkan diadopsi menjadi budaya betawi seperti musik gambus yang kemudian dikembangkan menjadi musik marawis, musik hadrah, tari zapin, dsb. Akan tetapi masih terdapat pemertahanan budaya yang bagi penulis terasa sangat tegas dan kontroversial seperti ketatnya pemilihan suami untuk putri mereka dan pemeliharan nasab yang mengeksklusifkan mereka dari penduduk pribumi khususnya kalangan masyarakat Betawi.

Saran dari penelitian ini adalah besar harapannya agar dapat dilanjutkan penelitian lanjutan dengan pendalaman dari berbagai bidang keilmuan budaya seperti ilmu bahasa, ilmu susastra, ilmu sejarah dan ilmu antropologi, maupun keilmuan lainnya seperti ilmu sosial, ilmu politik, ilmu hukum, dll. di samping ilmu budaya sendiri.

Sehingga dapat terumuskan rujukan yang tepat guna memberikan kontribusi yang bermanfaat khususnya kepada masyarakat keturunan Arab sebagai salah satu unsur yang telah memberikan sumbangsih sangat besar dalam mewujudkan kemerdekaan Negara Kesatuan Republik Indonesia.

\section{DAFTAR PUSTAKA}

[1] https://dictionary.cambridge.org/dictiona ry/english/diaspora. (Diakses Pada 8 maret 2017)

[2] http://kbbi.web.id/diaspora.(Diakses Pada 10 Oktober 2016.)

[3] E. Sujatmiko. Kamus IPS. Surakarta: Aksara Sinergi Media Cetakan 1. 2014

[4] G. Sumodiningrat dan R.Nugroho. Membangun Indonesia Emas. Jakarta: Elex Media Komputindo.2005

[5] P.K. Hitti. History of Arabs. Penerjemah: R. Cecep Lukman Yasin dan Dedi Slamet Riyadi, Jakarta: Serambi. 2010

[6] A.JR.Goldschmidt.A Concise History of the Middle East, 2nd revised ed. Egypt: Boulder. Westview and Cairo: American University in Cairo.1983

[7] Hamka. Sejarah Umat Islam. Selangor: PTS Media Group Sdn Bhd.2016

[8] D.Fromkin. A Peace to End All Peace: The Fall of the Ottoman Empire and the Creation of the Modern Middle East. New York: Owl.1989

[9] C. Hillenbrand.Perang Salib Sudut Pandang Islam. Penerjemah: Heryadi. Jakarta: Serambi.1999

[10] Sulistiono, Budi. http://www.rabithahalawiyah.org/id/kontribusi-komunitasarab-di-jakarta-abad-19-dan-awalabad-20-masehil .(Diakses Pada 8 maret 2017)

[11] Mobini, Kesheh, Natalie, The Hadrami Awakening: Community and Identity in the Netherlands East Indies 1900-1942, New York, 1999, reprinted 2004, Cornell Southeast Asia Program Publications.

[12] F. Daftari. Tradisi-tradisi Intelektual Islam. Jakarta: Erlangga. 2011

[13] H. Barakat. The Arab World: Society, Culture, and State. Los Angeles: University of California Press. 1993

[14] U. Farukh. Al- 'Arab Wa Al-Islam Fi AlHaudl Asy-Syarqi Min Al-Bahr Al-Abyad Al-Mutawassitah. Beirut: Dar Al-Kutub. 1996

[15] J. Al-Omari. Understanding the Arabic Culture. Oxford: Spring Hill Road. 2008

[16] A. Aziz. Chiefdom Madinah. Tangerang Selatan: Alvabet. 2011 